\title{
Aboriginal childhood overweight and obesity: the need for Aboriginal designed and
} led initiatives

\section{Simone L Sherriffa,b,c,e, Louise A Baurr,c, Michael G Lamberta, Michelle L Dickson” ${ }^{b}$, Sandra J Eades ${ }^{d}$ and Sumithra Muthayyaa,b,c}

a Sax Institute, Sydney, NSW, Australia

b School of Public Health, University of Sydney, NSW, Australia

c Children's Hospital Westmead Clinical School, Sydney Medical School, University of Sydney, NSW, Australia

${ }^{d}$ Faculty of Medicine, Dentistry and Health Sciences, University of Melbourne, VIC, Australia

${ }^{e}$ Corresponding author: simone.sherriff@saxinstitute.org.au

\section{Article history}

Publication date: December 2019

Citation: Sherriff SL, Baur LA, Lambert MG, Dickson ML, Eades SJ, Muthayya S. Aboriginal childhood overweight and obesity: the need for Aboriginal designed and led initiatives. Public Health Res Pract. 2019;29(4):e2941925.

https://doi.org/10.17061/phrp2941925

\section{Key points}

- Overweight and obesity rates are high and are increasing in Aboriginal children in Australia, the majority of whom now live in non-remote areas

- Very few policies and guidelines for obesity prevention and treatment exist for Australian children, especially Aboriginal children

- The effectiveness and reach of prevention and treatment initiatives targeting childhood overweight and obesity for Aboriginal children is largely unknown

- Meaningful engagement of Aboriginal communities and empowering them to have control over programs that affect their children's health and wellbeing is more likely to result in positive health outcomes

\section{Abstract}

Childhood obesity poses an urgent and serious public health challenge in Australia. Aboriginal children are more profoundly affected than nonAboriginal children, with the gap in weight status between the two groups widening, indicating an increased risk of metabolic disorders earlier in life. Obesity is the second biggest contributor (16\%) to the gap in health status between Aboriginal and non-Aboriginal people. The bulk of this gap is attributable to people living in non-remote settings who make up $81 \%$ of the total Aboriginal population in Australia. The complex interplay of socioenvironmental factors that contribute to obesity are well known and include prolonged financial stress associated with food insecurity, urbanisation, substandard and overcrowded housing, and lack of adequate access to health services. In addition, Aboriginal people, specifically, contend with the loss of traditional lands, and poor dietary behaviours due to the transition from traditional to Western diets as a result of colonisation. There are very few national policies and guidelines for obesity prevention and treatment for Australian children. This is especially the case for Aboriginal children. Most Australian states and territories have a suite of programs targeting obesity in childhood through healthy eating and active living strategies but with the exception of a few programs, the reach and effectiveness among Aboriginal children is either not known or has not been adequately assessed. Where programs have assessed Aboriginal participation, completion rates have generally been lower compared with the general population. The problem cannot be addressed without proper Aboriginal governance and leadership, and collaborative program development for Aboriginal-specific obesity interventions. Meaningful engagement and empowering Aboriginal communities to have control over programs that affect their health and wellbeing are more likely to result in positive health outcomes. Importantly, appropriate funding and support is essential to simultaneously facilitate the building of an Aboriginal health workforce to develop, coordinate, deliver and evaluate programs. 


\section{Background}

Childhood obesity is a serious and growing public health concern in Australia. Around one in four children aged 5-17 years is currently affected by overweight or obesity. ${ }^{1}$ A key challenge with this problem is that it is unevenly distributed. Rates are higher among Aboriginal children and others who experience greater socio-economic disadvantage, with the gap widening over the past two decades such that the most disadvantaged are most at risk. $^{2}$ Obesity is the second-highest contributor (16\%) to the health gap between Aboriginal and non-Aboriginal people. ${ }^{3}$ The bulk of this gap is attributable to Aboriginal children and adults living in non-remote areas, who make up $81 \%$ of the Aboriginal population in Australia. ${ }^{3,4}$

Aboriginal children have higher rates of obesity and combined overweight and obesity compared with nonAboriginal children at various ages (Table 1), indicating an increased vulnerability to metabolic disorders earlier in life. 5,6 Data from the Western Australian Children's Diabetes Database (children and adolescents aged $<17$ years) found that Aboriginal children had a diagnosis rate of type 2 diabetes that was 18 times higher than that of non-Aboriginal children. ${ }^{7}$ A NSW population-based cohort study also showed that Aboriginal children were at a higher risk of developing early signs of kidney disease if they had excess weight or obesity, compared with nonAboriginal children. ${ }^{8}$

The development of childhood obesity involves a complex set of inter-related biological and environmental factors, many of which are more likely to affect children from Aboriginal and lower socio-economic backgrounds. The intergenerational cultural, socio-economic and political impact of Australia's colonisation have led to poor nutrition and health including the forced removal of Aboriginal people from traditional lands and a resultant inability to access traditional food sources as Aboriginal people became more urbanised, were forced to consume an energy-dense Western diet and move away from their traditional lifestyle. ${ }^{9}$ Changes in the food environment and the impact of food marketing have resulted in takeaway and convenience foods becoming inexpensive and readily available ${ }^{10}$ and an attractive alternative for disadvantaged families, which ultimately leads to an obesogenic lifestyle. These changes are major contributors to increased obesity prevalence and have influenced the dramatic rise of nutrition-related disorders in Aboriginal communities. Other factors specific to Aboriginal people are recognised as a legacy of colonisation, including social inequality, prolonged financial stress associated with food insecurity, high rates of incarceration, lower levels of education, substandard and overcrowded housing, and inadequate access to healthcare. ${ }^{9}$

This paper reviews available evidence on programs and policies for obesity prevention and treatment for Aboriginal children and provides recommendations for improved outcomes.

\section{Existing Australian child obesity policies and programs for Aboriginal children and adolescents}

A recent review applied the INFORMAS Healthy Food Environment Policy Index on 42 national, state and territory policies related to food environments, and found that Australia is meeting best practice in the implementation of some policies. ${ }^{11,12}$ These included food labelling, no GST on fruits and vegetables, monitoring population body weight and national guidelines on healthy eating. However, there is much work left to be done to address unhealthy diets, such as the restriction of the promotion of unhealthy foods to children, implementation of taxes on unhealthy foods and a comphrehensive implementation plan linked to needs at the regional, state and national levels. ${ }^{11}$ Even though several of these policies mention that Aboriginal people are a population of interest, currently at the national and state levels there is a lack of policies and guidance

Table 1. Overweight and obesity prevalence (\%) in Aboriginal children in 2012-13ª

\begin{tabular}{|c|c|c|c|c|}
\hline \multirow[b]{2}{*}{ Age group (years) } & \multicolumn{2}{|c|}{$\begin{array}{l}\text { Combined } \\
\text { overweight and obesity (\%) }\end{array}$} & \multicolumn{2}{|c|}{ Obesity (\%) } \\
\hline & $\begin{array}{l}\text { Aboriginal } \\
\text { children }\end{array}$ & $\begin{array}{l}\text { Non-Aboriginal } \\
\text { children }\end{array}$ & $\begin{array}{l}\text { Aboriginal } \\
\text { children }\end{array}$ & $\begin{array}{l}\text { Non-Aboriginal } \\
\text { children }\end{array}$ \\
\hline $2-4$ & 22.7 & 22.9 & 6.0 & 5.1 \\
\hline $5-9$ & 26.9 & 24.1 & 11.2 & 7.6 \\
\hline $10-14$ & 37.4 & 27.1 & 11.8 & 6.3 \\
\hline $15-17$ & 34.9 & 24.2 & 14.2 & 7.4 \\
\hline $18-24$ & 55.3 & 36.1 & 28.4 & 14.4 \\
\hline
\end{tabular}


for programs that are specifically aimed at addressing Aboriginal childhood obesity. ${ }^{13}$

Australian states and territories have several programs targeting childhood obesity, but their reach and effectiveness among Aboriginal children is either not known or has been inadequately assesed. Two examples are the 'Munch and Move' program run in childcare centres and the 'Live Life Well @ School' program at schools in New South Wales (NSW). An evaluation conducted on these programs did not report findings for Aboriginal children separately. ${ }^{14,15}$

One exception, however, is the NSW 'Go4Fun' program, which is a free 10-week program that focuses on improving nutrition habits, physical activity and confidence among children aged $7-13$ years who are above a healthy weight. Six percent of the children participating in Go4Fun between 2009 and 2012 were Aboriginal. However, a process evaluation of the program showed that Aboriginal children were far less likely to complete the program $^{16}$ and highlighted a need for more culturally appropriate strategies and better engagement with Aboriginal communities. In an effort to adapt this program to be culturally relevant for Aboriginal children, Aboriginal Go4Fun Advisory Groups were established through four Local Health District areas in NSW and the resources used were modified to include Aboriginalspecific content and a more family-based approach. A pilot evaluation of the modified 'culturally adapted' program on a small number of Aboriginal children was undertaken and has shown some early improvements in the children's health behaviours. However, due to the small number of children in the pilot evaluation, further work is required to provide greater understanding of the effectiveness of the adaptation. ${ }^{17}$

The Queensland 'Parenting, Eating and Activity for Child Health' (PEACH) program has also been reviewed with the view of culturally adapting the program for Aboriginal families. PEACH is a 6-month, family-focused, healthy lifestyle program for children aged 5-11 years who are above a healthy weight. This program targeted parents and/or carers as agents of change and was delivered via parent-only group sessions, while their children participated in fun, noncompetitive activity sessions. ${ }^{18}$ The review found that $5 \%$ of the families who participated were Aboriginal, but no details on outcomes for Aboriginal families were available. Consultations held with Aboriginal families and organisations highlighted the need for genuine partnerships with local Aboriginal communities and a more family-focused approach. It was also found that a parent-led approach may not be appropriate for Aboriginal communities. ${ }^{19}$ The PEACH program has now been discontinued and the cultural adaptation did not proceed due to insufficient time to build genuine partnerships and input from Aboriginalspecific providers.

Programs specifically targeting overweight and obesity in Aboriginal children are particularly scarce: the majority of programs focus on healthy lifestyles mainly for Aboriginal adults in rural and remote communities. Aboriginal Community Controlled Health Services (ACCHSs) across Australia also deliver healthy lifestyle programs aimed at addressing overweight and obesity in their local communities. ${ }^{20}$ Unfortunately, due to limited resources and funding bodies often not allocating funds for evaluation, the participation rates for children and other outcomes for many of these programs are largely not published or available. ${ }^{21}$ Better data will help support the development of effective programs to address childhood obesity and associated health consequences among Aboriginal communities.

\section{Considerations for future work}

There is evidence that health programs and policies are more relevant and lead to greater health outcomes when co-created with the intended end users. ${ }^{22,23}$ The current approach to addressing overweight and obesity among Aboriginal children is disempowering communities and does not address the inequalities that exist. ${ }^{24}$ Governments need to work together with Aboriginal communities to develop and implement programs and policies that better address inequities observed in childhood obesity and other health conditions. This could include ensuring genuine co-design of mainstream health promotion and obesity prevention programs and supporting the development and evaluation, and potentially scaling up of programs developed by Aboriginal communities.

In order for programs targeting Aboriginal people to be effective, governments must commit to selfdetermination for Aboriginal communities and ensure Aboriginal governance for all policy, program and implementation work. ${ }^{25}$ This will require governments to share power and control ${ }^{26}$ with communities. ${ }^{27,28}$ Aboriginal leadership must be embraced at all levels to drive the development of relevant programs and policies. There is also a need for Aboriginal people and organisations to define program success, and lead ongoing measurement and evaluation.

There needs to be increased funding and resources for Aboriginal health workforce training opportunities that specialise in areas related to child obesity. Local ACCHSs, which have long been a driving force in defining directions for Aboriginal healthcare delivery, leadership and design, must be engaged in this work. State governments need to work with these organisations that are best placed to coordinate and deliver such programs and can ensure good participation and acceptance in the community. ${ }^{29}$ Aboriginal communities that design and run programs often remove many of the barriers faced by Aboriginal families - such as lack of transport, discrimination, lack of trust, shame - and ensure the programs are culturally appropriate and relevant. The ACCHS model for delivering comprehensive primary 
health care is a model that provides an example of best practice for many other populations and communities. ${ }^{29}$

\section{Conclusion}

Urgent action is needed to tackle the childhood obesity epidemic for Aboriginal children. Strengthsbased, whole-of-community approaches underpinned by self-determination, that address multiple risk factors simultaneously are likely to be most effective at reducing obesity in Aboriginal children. Evaluation and dissemination of findings need to be prioritised in program design, along with appropriate funding and support to facilitate the building of an Aboriginal health workforce to develop, coordinate, deliver and evaluate programs.

\section{Acknowledgements}

We acknowledge Aboriginal and Torres Strait Islander people as the traditional custodians of Australia and pay our respects to their Elders past, present and future. This work was supported by The Australian Prevention Partnership Centre, funded through the National Health and Medical Research Council of Australia (NHMRC) Partnership Centre grant scheme (grant ID: GNT9100001) with the Australian Government Department of Health, the NSW Ministry of Health, ACT Health and the HCF Research Foundation. The work was also funded by grants from the NHMRC through the Study of Environment on Aboriginal Resilience and Child Health (SEARCH) (\#358457, \#1023998 and \#1035378). Simone Sherriff was supported by a Turner PhD scholarship from the Charles Perkins Centre, University of Sydney.

\section{Peer review and provenance}

Externally peer reviewed, invited.

\section{Competing interests}

None declared.

\section{Author contributions}

SS and SM drafted the manuscript. LB, MD, SE and ML reviewed the manuscript and provided comments.

\section{References}

1. Australian Bureau of Statistics. National health survey: first results 2014-15. Canberra: ABS; 2015 [cited 2019 Nov 6]. Available from: https://www.abs.gov.au/ AUSSTATS/abs@.nsf/DetailsPage/4364.0.55.0012014-15
2. Chung A, Backholer K, Wong E, Palermo C, Keating C, Peeters A. Trends in child and adolescent obesity prevalence in economically advanced countries according to socioeconomic position: a systematic review. Obes Rev. 2016;17(3):276-95.

3. Vos T, Barker B, Begg S, Stanley L, Lopez AD. Burden of disease and injury in Aboriginal and Torres Strait Islander Peoples: the Indigenous health gap. Int J Epidemiol. 2009;38(2):470-7.

4. Australian Bureau of Statistics. Census of population and housing - counts of Aboriginal and Torres Strait Islander Australians, 2016. Canberra: ABS; 2018 [cited 2019 Nov 6]. Available from: www.abs.gov.au/AUSSTATS/abs@.nsf/ Lookup/2075.0Main+Features202016?OpenDocument

5. Australian Bureau of Statistics. Australian Aboriginal and Torres Strait Islander health survey: updated results, 2012-13. Canberra: ABS; 2014 [cited 2019, Nov 6]. Available from: www.abs.gov.au/ausstats/abs@.nsf/mf/4727.0.55.006

6. Thurber KA, Dobbins T, Neeman T, Banwell C, Banks E. Body mass index trajectories of Indigenous Australian children and relation to screen time, diet, and demographic factors. Obesity. 2017;25(4):747-56.

7. McMahon SK, Haynes A, Ratnam N, Grant MT, Carne CL, Jones TW, et al. Increase in type 2 diabetes in children and adolescents in Western Australia. Medical J Aust. 2004;180(9):459-61.

8. Kim S, Macaskill P, Hodson EM, Daylight J, Williams R, Kearns R, et al. Beginning the trajectory to ESKD in adult life: albuminuria in Australian aboriginal children and adolescents. Pediatr Nephrol. 2017;32(1):119-29.

9. Willows ND, Hanley AJ, Delormier T. A socioecological framework to understand weight-related issues in Aboriginal children in Canada. Appl Physiol Nutr Metab. 2012;37(1):1-13.

10. Halford JC, Boyland EJ, Hughes GM, Stacey L, McKean S, Dovey TM. Beyond-brand effect of television food advertisements on food choice in children: the effects of weight status. Public Health Nutr. 2008;11(9):897-904.

11. Sacks G for the Food-EPI Australia project team. Policies for tackling obesity and creating healthier food environments: scorecard and priority recommendations for the South Australian government. Melbourne: Deakin University; 2017 [cited 2019 Nov 6]. Available from: www. opc.org.au/downloads/food-policy-index/SA-food-epireport.pdf

12. Sacks G for the Food-EPI Australia project team. Policies for tackling obesity and creating healthier food environments: scorecard and priority recommendations for the Australian Federal government. Melbourne: Deakin University 2017 [cited 2019 Nov 6]. Available from: www. opc.org.au/downloads/food-policy-index/FED-food-epireport.pdf 
13. Browne J, Hayes R, Gleeson D. Aboriginal health policy: is nutrition the 'gap' in 'Closing the Gap'? Aus N Z J Public Health. 2014;38(4):362-9.

14. Bravo A, Innes-Hughes C, O'Hara BJ, McGill B, Rissel C. Live Life Well @ School: evidence and evaluation summary 2008-2015. Sydney: NSW Ministry of Health; 2016 [cited 2019 Nov 7]. Available from: www.health.nsw. gov.au/heal/Publications/LLW@S-report.pdf

15. Lockeridge A, Innes-Hughes C, O'Hara BJ, McGill B, Rissel C. Munch \& Move: evidence and evaluation summary. Sydney: NSW Ministry of Health; 2015 [cited 2019 Nov 6]. Available from: www.health.nsw.gov.au/heal/ Publications/Munch-Move-Evaluation-Summary.pdf

16. Welsby D, Nguyen B, O'Hara BJ, Innes-Hughes C, Bauman A, Hardy LL. Process evaluation of an up-scaled community based child obesity treatment program: NSW Go4Fun®. BMC Public Health. 2014;14(1):140.

17. Innes-Hughes C, Rissel C, Henderson L, Radvan D. Cultural adaptation of the Go4Fun program for delivery with Aboriginal communities in NSW report. Sydney: NSW Ministry of Health; 2016. Copy available from authors.

18. Williams SL, Lippevelde W, Magarey A, Moores CJ, Croyden D, Esdaile E, et al. Parent engagement and attendance in PEACH ${ }^{\mathrm{TM}}$ QLD - an up-scaled parentled childhood obesity program. BMC Public Health. 2017;17(1):559.

19. Binge L. PEACH adaption project for Aboriginal and Torres Strait Islander families: final report (phase 1). Brisbane: Queensland University of Technology; 2015 [cited 2019 Nov 6]. Available from: healthinfonet.ecu.edu. au/healthinfonet/getContent. php?linkid=562545\&title=PE $\mathrm{ACH}+$ adaption+project+for+Aboriginal+and+Torres+Stra it+Islander+families\%3A+final+report+\%28phase+1\%29

20. Aboriginal Health \& Medical Research Council of NSW. 10 out of 10 deadly health stories - nutrition and physical activity. Sydney: AH\&MRC; 2009 [cited 2019 Nov 14]. Available from: www.ahmrc.org.au/wp-content/ uploads/2019/07/ahmrc_cd_2010_10_out_of_10_deadly_ health_stories.pdf
21. Schwarzman J, Nau T, Bauman A, Gabbe BJ, Rissel C, Shilton T, Smith BJ. An assessment of program evaluation methods and quality in Australian prevention agencies. Health Promot J Austr. 2019;10.1002/hpja.287.

22. Hertzman C, Siddiqi A. Population health and the dynamics of collective development. In: Hall PA, ed. Successful societies: how institutions and culture affect health. Cambridge: Cambridge University Press; 2009. p. 23-52.

23. Ng JY, Ntoumanis N, Thøgersen-Ntoumani C, Deci EL, Ryan RM, Duda JL, et al. Self-determination theory applied to health contexts: A meta-analysis. Perspect Psychol Sci. 2012;7(4):325-40.

24. Marmot M. Status syndrome: How your social standing directly affects your health: A\&C Black; 2005.

25. Behrendt L, Porter A, Vivian A. Indigenous selfdetermination within the justice context. Sydney: Jumbunna Indigenous House of Learning; 2017 [cited 2019 Nov 6]. Available from: opus.lib.uts.edu.au/ handle/10453/94284

26. Sherriff SL, Miller H, Tong A, Williamson A, Muthayya S, Redman $S$, et al. Building trust and sharing power for co-creation in Aboriginal health research: a stakeholder interview study. Evidence \& Policy: A Journal of Research, Debate and Practice. 2019;15(3):371-92.

27. Phillips G. Dancing with power: Aboriginal health, cultural safety and medical education. Melbourne: Monash University; 2015 [cited 2019 Nov 7]. Available from: pdfs.semanticscholar.org/68df/ 9e737a48d1b88e6855b451ed1d45c5da6367. pdf?_ga=2.209884501.1397996951.1573090561510371040.1567549577

28. Deci EL, Ryan RM. Motivation, personality, and development within embedded social contexts: an overview of self-determination theory. In: Ryan RM, ed. The Oxford handbook of human motivation. Oxford: Oxford University Press; 2012. p. 85-107.

29. Aboriginal Health \& Medical Research Council. Aboriginal communities improving Aboriginal health: an evidence review on the contribution of Aboriginal Community Controlled Health Services to improving Aboriginal health. Sydney: AH\&MRC; 2015 [cited 2019 Nov 6]. Available from: n8p4t5m5.stackpathcdn.com/wp-content/ uploads/2019/07/ahmrc_research_2015_research_ evidence_report.pdf



(C) 2019 Sherriff et al. This article is licensed under the Creative Commons Attribution-NonCommercial-ShareAlike 4.0 International Licence, which allows others to redistribute, adapt and share this work non-commercially provided they attribute the work and any adapted version of it is distributed under the same Creative Commons licence terms. See: www.creativecommons.org/licenses/by-nc-sa/4.0/ 